\title{
The Binding of Benzoarylsulfonamide Ligands to Human Carbonic Anhydrase is Insensitive to Formal Fluorination of the Ligand
}

\section{Citation}

Lockett, Matthew R., Heiko Lange, Benjamin Breiten, Annie Heroux, Woody Sherman, Dmitrij Rappoport, Patricia O. Yau, Philip W. Snyder, and George M. Whitesides. 2013. "The Binding of Benzoarylsulfonamide Ligands to Human Carbonic Anhydrase Is Insensitive to Formal Fluorination of the Ligand." Angewandte Chemie 125, no. 30: 7868-7871.

\section{Published Version}

doi:10.1002/ange.201301813

\section{Permanent link}

http://nrs.harvard.edu/urn-3:HUL.InstRepos:12362620

\section{Terms of Use}

This article was downloaded from Harvard University's DASH repository, and is made available under the terms and conditions applicable to Open Access Policy Articles, as set forth at http:// nrs.harvard.edu/urn-3:HUL.InstRepos:dash.current.terms-of-use\#OAP

\section{Share Your Story}

The Harvard community has made this article openly available.

Please share how this access benefits you. Submit a story.

Accessibility 


\section{The Binding of Benzoarylsulfonamide Ligands to Human Carbonic Anhydrase is Insensitive to Formal Fluorination of the Ligand}

Heiko Lange, ${ }^{\mathrm{a}, \dagger}$ Matthew R. Lockett,,${ }^{\mathrm{a}, \dagger}$ Benjamin Breiten, ${ }^{\mathrm{a}}$ Annie Heroux, ${ }^{\mathrm{b}}$ Woody Sherman, ${ }^{\mathrm{c}}$ Dmitrij Rappoport, ${ }^{\mathrm{a}}$ Patricia O. Yau, ${ }^{\mathrm{a}}$ Philip W. Snyder, ${ }^{\mathrm{a}}$ George M. Whitesides ${ }^{\mathrm{a}, \mathrm{d}, *}$

${ }^{a}$ Department of Chemistry and Chemical Biology, Harvard University 12 Oxford Street, Cambridge, MA 02138

${ }^{\mathrm{b}}$ National Synchrotron Light Source, Brookhaven National Laboratory 725 Brookhaven Avenue, Upton, NY 11973

${ }^{\mathrm{c}}$ Schrödinger Inc.

120 West $45^{\text {th }}$ Street, New York, NY 10036

${ }^{\mathrm{d}}$ Wyss Institute for Biologically Inspired Engineering, Harvard University 60 Oxford Street, Cambridge, MA 02138

* Author to whom correspondence should be addressed: gwhitesides@ gmwgroup.harvard.edu

${ }^{\dagger}$ These authors contributed equally. 
The hydrophobic effect (or the aggregated effects that we call "the hydrophobic effect") underlies the binding of many ligands to proteins. It involves three molecular participants: the surface of the binding pocket of the protein, the surface of the ligand, and the networks of water molecules that fill the pocket and surround the ligand. The molecular-level mechanism of the hydrophobic effect in protein-ligand binding remains a subject of substantial controversy. ${ }^{[1,2]}$ There are three primary questions of interest: i) "Do hydrophobic effects reflect the release of structured, and hence entropically unfavorable, water from hydrophobic surfaces when the ligand and surface of the binding pocket come into contact?"; ii) "Do hydrophobic effects represent the release of free-energetically unfavorable water from hydrogen-bonded networks in the binding pocket or displacement by the ligand, and the release of free-energetically unfavorable (although perhaps different) waters from the hydrophobic surface of the ligand?"; and iii) "How important in free energy are the contact interactions between the protein and the ligand in the binding pocket?".

In a previous examination of these questions, ${ }^{[3]}$ we compared the binding of a series of heteroarylsulfonamide ligands, and their "benzo-extended" analogs (Scheme 1), to human carbonic anhydrase II (HCA; EC 4.2.1.1). In these binding events, the addition of a benzo group: i) increased the hydrophobic surface area (and the volume) of the ligand; ii) generated two new van der Waals contacts between the ligand and hydrophobic wall of HCA; but iii) did not result in a significant increase in the area of contact between the hydrophobic surfaces of the protein and ligand. The free energy of binding of the arylsulfonamide ligands increased with the additional surface area buried upon binding from the benzo-extension by $-20 \mathrm{cal} \mathrm{mol}^{\square} \AA^{\square 2},{ }^{[3]}$ an amount expected for normal hydrophobic effects $\left(-20 \text { to }-33 \text { cal mol }{ }^{\square 1} \AA^{\square 2}\right)^{[4]}$. The heat capacity of binding $\left(\Delta C_{\mathrm{p}}{ }^{\circ}\right)$ of the benzo-extended ligands was more negative than the corresponding 


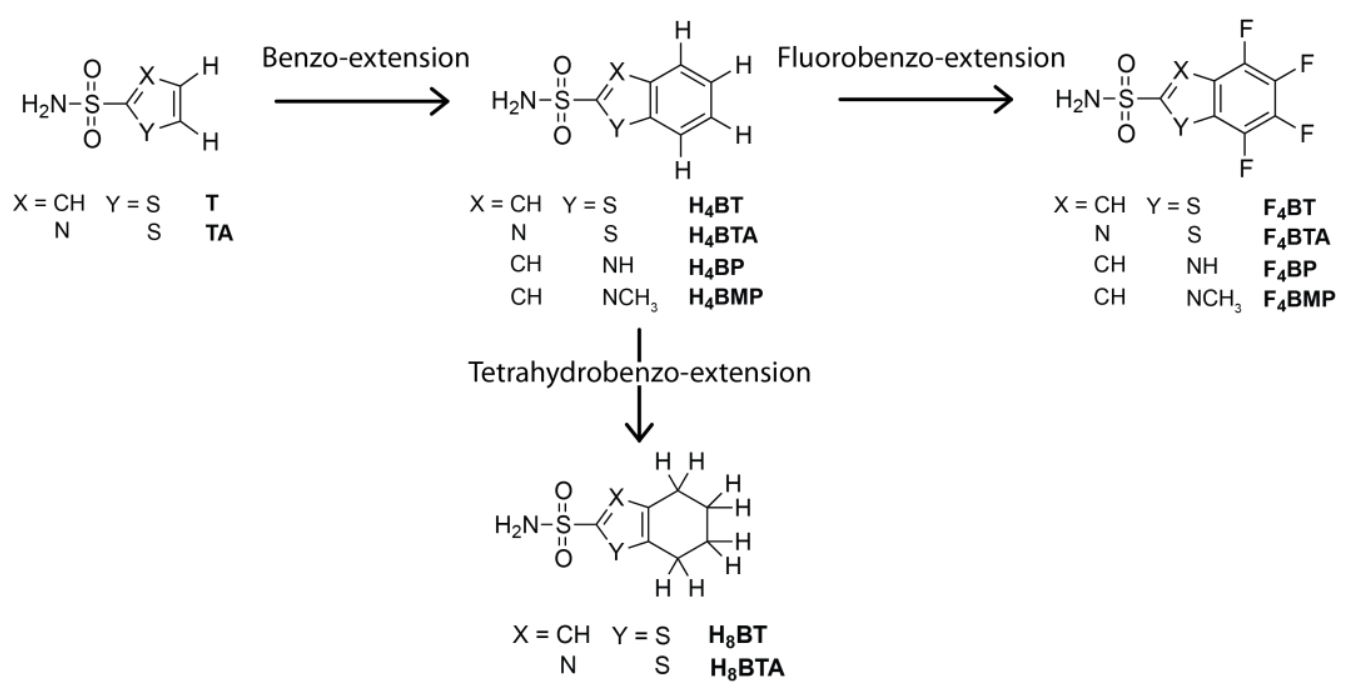

Scheme 1. Arylsulfonamide ligands. Hydrophobic surface area is added to the heterocyclic ligands by: a "benzo-extension", denoted with a $\mathbf{H}_{4}$; a "fluorobenzo-extension", denoted with a $\mathbf{F}_{4}$; or a "tetrahydrobenzo-extension", denoted with a $\mathbf{H}_{\mathbf{8}}$. The bold letters are the ligand acronyms: $(\mathbf{B}) \mathbf{T A}=($ benzo)thiazole $;(\mathbf{B}) \mathbf{T}=($ benzo)thiophene; $(\mathbf{B}) \mathbf{P}=($ benzo $)$ pyrrole $;(\mathbf{B}) \mathbf{M P}=$ $N$-methyl(benzo)pyrrole. 
arylsulfonamide ${ }^{[3]}$ — a change commonly considered to be a sign of a hydrophobic interaction. ${ }^{[5]}$

We drew two conclusions pertinent to protein-ligand interactions from the previous study: ${ }^{[3]}$ i) the balance of enthalpy and entropy responsible for the differences in the partitioning of a ligand, and its benzo-extended analog, between octanol and buffer is not the same as that responsible for differences in the binding of these ligands to HCA; and ii) the increased binding affinity of the benzo-extended ligands to HCA results from an increased favorability in the enthalpy of binding, and not from an increased entropy of binding. The enthalpy-driven binding observed between these ligands and HCA is not compatible with the mechanism of the hydrophobic effect proposed by Kauzmann and Tanford $(\mathrm{KT}),{ }^{[4,6]}$ but is similar to those observed in other protein-ligand systems. ${ }^{[7-9]} \mathrm{We}$-along with Berne,${ }^{[10]}$ Chandler, ${ }^{[11]}$ Friesner, ${ }^{[12,}$ ${ }^{13]}$ Klebe,${ }^{[14]}$ Ladbury, ${ }^{[15,16]}$ Lemieux ${ }^{[17]}$ Rossky,${ }^{[18,19]}$ and Toone ${ }^{[20,21]}$-attribute this type of enthalpy-dominated hydrophobic effect to the release of water from the binding pocket upon binding of the ligand. Similar thermodynamic signatures characterize binding of the benzo and the tetrahydrobenzo derivative of $\mathbf{T}$ (see Scheme 1). ${ }^{[3]}$

The objective of this work was to determine if replacing the four $\mathrm{C}-\mathrm{H}$ bonds of the benzo moiety with four $\mathrm{C}-\mathrm{F}$ bonds (i.e., "fluorobenzo-extension") would change the hydrophobic interactions of these ligands with HCA. Fluorocarbons are commonly believed to be "more hydrophobic" than homologous hydrocarbons, ${ }^{[22,23]}$ but typical measures of hydrophobicitywhen corrected for differences in surface area — are very similar, if not indistinguishable..$^{[9,23,24]}$ We measured the partitioning of the benzo- and fluorobenzo-extended ligands between buffer and octanol, and found the surface area-corrected hydrophobicity of the ligands increases (by $1.1 \mathrm{cal} \mathrm{mol}^{\square 1} \AA^{\square 2}$ ) upon fluorination (summarized in the Supporting Information (SI)). 


\section{Benzo- and fluorobenzo-extended ligands bind to HCA with similar geometry. Crystal}

structures of HCA complexed with $\mathbf{F}_{4} \mathbf{B T A}, \mathbf{H}_{4} \mathbf{B T A}$, and $\mathbf{H}_{8} \mathbf{B T A}$ (Figure 1) show that the geometry of binding of these ligands is similar in orientation despite their differences in shape, volume, and surface. The geometries of binding of $\mathbf{F}_{4} B T, \mathbf{H}_{4} \mathbf{B T}$, and $\mathbf{H}_{8} \mathbf{B T}$ are also conserved (see SI).

Careful inspection of the crystal structures of $\mathbf{H}_{4}$ BTA and $\mathbf{F}_{4}$ BTA reveals that fluorination of the ligand shifts its position within the binding pocket by $0.7 \AA$ (Figure 1D) while the positions of the side chains of the amino acids lining the binding pocket of HCA do not change. We attribute this shift of $\mathbf{F}_{4} \mathbf{B T A}$ to an increased number of unfavorable interactions between the ligand and the binding pocket (Figure 1E); in particular, the Coulombic repulsion between the fluorine atom on the ligand and the carbonyl of Thr $200,{ }^{[25]}$ a 3.0 A distance.

The atomic composition of the benzo-extension does not affect binding affinity. We measured the enthalpies of binding $\left(\Delta H^{\mathrm{o}}\right.$ bind $)$ and the association constants $\left(K_{\mathrm{a}}\right)$ for the series of ligands in Scheme 1 using isothermal titration calorimetry (ITC), and estimated the free energies ( $\Delta G^{\mathrm{o}}$ bind) and entropies (-T $\Delta S^{\mathrm{o}}$ bind) of binding. To account for differences in the $\mathrm{p} K_{\mathrm{a}}$ of each ligand, we corrected the measured thermodynamic parameters to represent the binding of the sulfonamide anion to HCA (details in the SI). ${ }^{[26]}$

Remarkably, values of $\Delta G^{\mathrm{o}}$ bind of the benzo- and fluorobenzo-extended compounds are indistinguishable at a $90 \%$ confidence level (Figure 2A). Values of $\Delta G^{\mathrm{o}}$ bind, combined with the overall conserved binding geometry of each set of benzo- and fluorobenzo-extended ligands 
A)

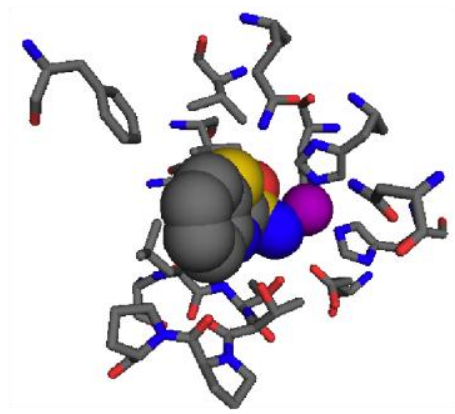

D)

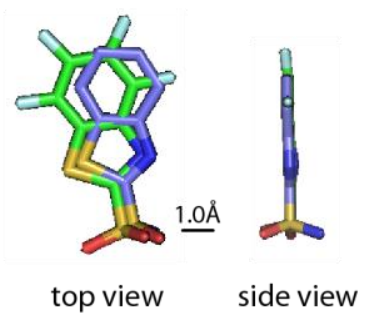

B)

E)
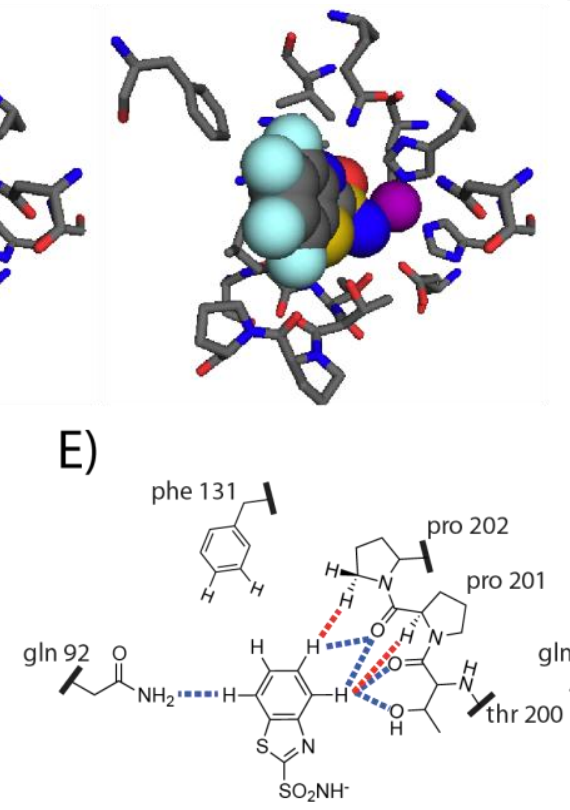

C)

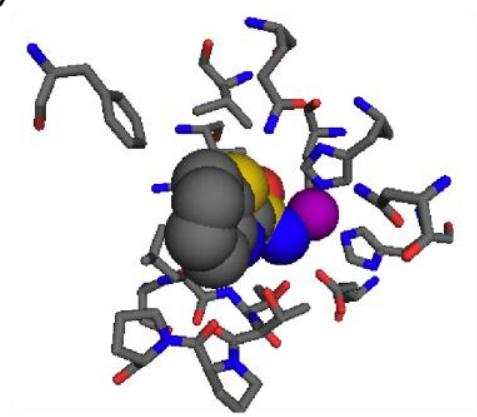

F)

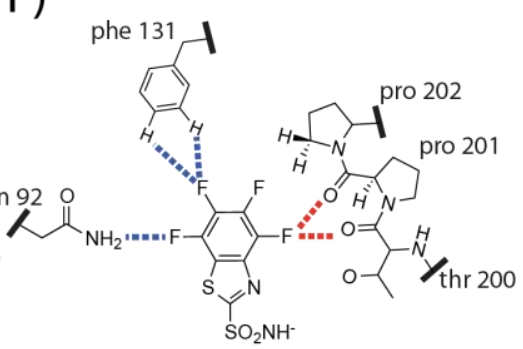

Figure 1. Crystal structures of the active site of HCA complexed with A) $\mathbf{H}_{4}$ BTA, B) F $_{4}$ BTA, and C) $\mathbf{H}_{8}$ BTA. The $\mathrm{Zn}^{+2}$ ion is represented by a purple sphere in each structure. D) An overlay of the heavy atoms of the $\mathbf{H}_{4}$ BTA (blue) and $\mathbf{F}_{4}$ BTA (green) ligands from aligned crystal structures. Diagrams of the amino acid residues in contact with the E) benzo-extended portion of $\mathbf{H}_{4}$ BTA, and F) the fluorobenzo-extended portion of $\mathbf{F}_{4}$ BTA. Favorable interactions between the ligand and the protein are represented with a blue dashed line, and unfavorable interactions with a red dashed line. 
suggests that binding depends on a fine balance of interactions between HCA, the ligand, and molecules of water filling the pocket and surrounding the ligand, and that a simple analysis of interactions between the protein and ligand (Figure 1E), or of the physiochemical properties of the ligands, is insufficient to understand (or more importantly, predict) the energetics of binding. Our previous study of $\mathbf{H}_{4} \mathbf{B T}$ and $\mathbf{H}_{8} \mathbf{B T}$ showed that changes in the shape of the ligand also resulted in indistinguishable values of $\Delta G^{\mathrm{o}}{ }_{\text {bind }}{ }^{[3]}$

The increased binding affinity of TA (or T) upon benzo- and fluorobenzo-extension is an enthalpy-dominated hydrophobic interaction, and not the "classical hydrophobic" effect described by KT. We showed previously that the interactions between the benzo-extended ligands and HCA do not result from a "non-classical hydrophobic effect", ${ }^{27]}$ because the binding of $\mathbf{H}_{\mathbf{8}} \mathbf{B T}$ is also enthalpy-dominated. ${ }^{[3]}$ The partitioning of $\mathbf{H}_{\mathbf{4}}$ BTA and $\mathbf{F}_{\mathbf{4}}$ BTA from buffer into octanol (Figure 2B) is, however, an entropy-dominated hydrophobic effect, and in agreement with the KT model.

The release of water from the binding pocket, and not contact between the protein and ligand, affects binding affinity. Comparisons of the crystal structures of $\mathrm{H}_{4} \mathrm{BMP}$ and $\mathrm{H}_{4} \mathrm{BTA}$ (or $\mathbf{F}_{4}$ BMP and $\mathbf{F}_{4} \mathbf{B T A}$, Figure 3 ) show that the positions of the side chains of the amino acids lining the binding pocket of HCA do not change, even when the geometry of the bound ligand shifts significantly. The root-mean square deviation for the heavy atoms of the protein in the aligned structures is $0.185 \AA$ for $\mathbf{H}_{4} \mathbf{B M P}$ and $\mathbf{H}_{4}$ BTA, $0.214 \AA$ for $\mathbf{F}_{4}$ BMP and $\mathbf{F}_{4}$ BTA, and (for comparison) $0.200 \AA$ for $\mathbf{H}_{\mathbf{4}}$ BTA and $\mathbf{F}_{\mathbf{4}}$ BTA.

The values of $\Delta G^{\mathrm{o}}$ bind for $\mathbf{H}_{4} \mathbf{B M P}$ and $\mathbf{F}_{4} \mathbf{B M P}$ are also indistinguishable $\left(\Delta \Delta G^{\mathrm{o}}\right.$ bind $=0.7 \pm$ $0.1 \mathrm{kcal} \mathrm{mol}^{-1}$ ), and enthalpy-dominated. These results support our hypothesis that the increased binding affinity of the benzo-extended ligands is independent of the change in atomic 
A)
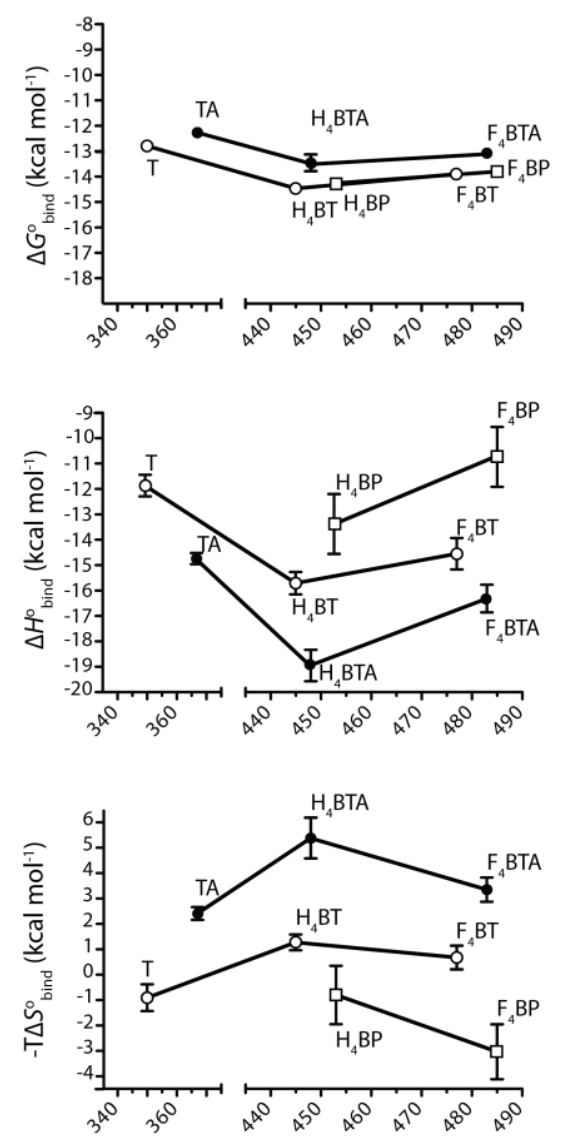

Solvent-accessible surface area $\left(\AA^{2}\right)$
B)
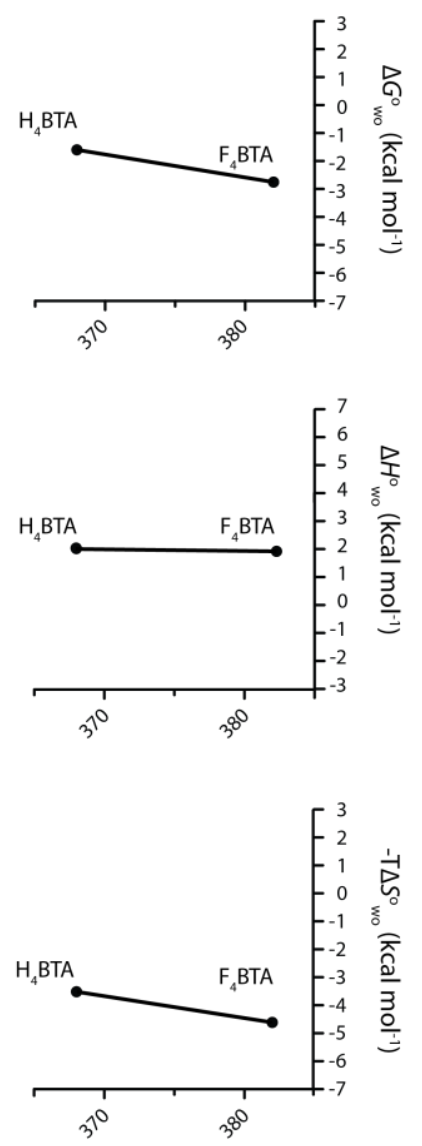

Accessible surface area $\left(\AA^{2}\right)$

Figure 2. A) Thermodynamics of binding of the anion of each arylsulfonamide ligand to HCA as a function of the difference in solvent-accessible surface area between the bound and unbound states of the ligand. Each datum is the average of at least seven independent measurements, and the error bars represent one standard deviation from the mean (many of the error bars for the values of $\Delta G^{\mathrm{o}}$ bind are too small to distinguish). B) Thermodynamics of partitioning of $\mathbf{H}_{4}$ BTA and $\mathbf{F}_{\mathbf{4}} \mathbf{B T A}$ from buffer to octanol; each datum is the average of three independent measurements. The equilibrium constants for partitioning from octanol to buffer of each sulfonamide were measured by a shake-flask method. Values for the enthalpy of partitioning of each ligand represent the difference between the enthalpy of dissolution into buffer and the 
enthalpy of dissolution into octanol. Values for the thermodynamics of partitioning and binding are corrected for the ionization of the sulfonamide group in the buffer phase. ${ }^{[3]}$ 
composition of the benzo group, and almost indistinguishable for three types of functional groups that have very different molecular properties.

While the $\Delta G_{\text {bind }}^{\mathrm{o}}$ is unchanged upon fluorination, we observe significant and compensating changes in $\Delta H^{\mathrm{o}}$ bind and $-\mathrm{T} \Delta S^{\mathrm{o}}$ bind (Figure 2A). To elucidate potential sources for the differences in the $\Delta H^{\mathrm{o}}$ bind and $-\mathrm{T} \Delta S^{\mathrm{o}}$ bind we calculated the molecular mechanics implicit solvent binding energy (with Prime MM-GBSA calculations ${ }^{[28]}$ ) of $\mathbf{H}_{4} \mathbf{B T A}$ and $\mathbf{F}_{\mathbf{4}} \mathbf{B T A}$, and decomposed these values into individual energetic components (i.e., Coulombic, van der Waals, desolvation, ligand strain, etc.). The differences between the individual components of the binding energy of $\mathbf{H}_{4}$ BTA and F $_{4}$ BTA are similar (less than $1.5 \mathrm{kcal} \mathrm{mol}^{-1}$ different, see SI) except for: the Coulombic term, which favors the binding of $\mathbf{H}_{4} \mathbf{B T A}$ by $5.8 \mathrm{kcal} \mathrm{mol}^{-1}$; and the desolvation term, which favors the binding of $\mathbf{F}_{4} \mathbf{B T A}$ by $8.2 \mathrm{kcal} \mathrm{mol}^{-1}$.

The crystal structures of $\mathbf{H}_{4}$ BTA and $\mathbf{F}_{4}$ BTA (Figure 1E) support the improved Coulombic interactions between $\mathbf{H}_{4}$ BTA and the binding pocket of $\mathrm{HCA}$; this picture is further supported by the more favorable $\Delta H^{0}$ bind of $\mathbf{H}_{4}$ BTA over $\mathbf{F}_{4}$ BTA. The desolvation of $\mathbf{F}_{4}$ BTA is more favorable than $\mathbf{H}_{4}$ BTA, and is consistent with the values of $-\mathrm{T} \Delta S_{\text {bind }}^{\mathrm{o}}$ (Figure $2 \mathrm{~A}$ ) and free energy and entropy of partitioning (Figure 2B) of both ligands. The free energy of desolvation of the ligand is a primary contributor, along with conformational energy, to the $-\mathrm{T} \Delta S^{\mathrm{o}}$ bind associated with protein-ligand binding. ${ }^{[29]} \mathrm{We}$ assume the role of the conformational entropy in the HCA-ligand complexes is minimal because of the rigidity of the binding pocket of HCA and the conserved binding geometry of each ligand; this rigidity stems from the fact that there is only a single, rotatable bond (the $\mathrm{Ar}-\mathrm{SO}_{2} \mathrm{NH}^{-}$bond) in the molecule.

The Prime MM-GBSA calculations predict a more favorable total free energy of binding of HCA with $\mathbf{F}_{4}$ BTA over $\mathbf{H}_{4} \mathbf{B T A}$ (by $<3.0 \mathrm{kcal} \mathrm{mol}^{-1}$ ). The zero-temperature model used in MM- 
GBSA calculations, however, tend to overestimate the predicted magnitude of $\Delta G^{\mathrm{o}}$ bind (by $\sim 3$ fold $\left.{ }^{[30]}\right)$. The adjusted value of $\Delta G^{\mathrm{o}}$ bind for the MM-GBSA calculations is within the experimental error of our ITC measurements, and agrees (qualitatively) with the indistinguishable values of $\Delta G_{\text {bind }}^{\mathrm{o}}$ we measured for $\mathrm{H}_{4} \mathrm{BTA}$ and $\mathbf{F}_{4}$ BTA.

\section{Different benzo-extensions cause similar effects on the water molecules inside the protein} pocket upon binding. Crystal structures of HCA complexed with $\mathrm{H}_{4}$ BTA or F $_{4}$ BTA show that fluorination of the benzo-extended ligands increases the number of localized (i.e., crystallographically resolvable) waters in the binding pocket of HCA from six to ten. We summarize the number of fixed molecules of water for the benzo- and fluorobenzo-extended BTA and BMP ligands in Table 1. This result mirrors our previous study, ${ }^{[3]}$ which showed that the addition of the benzo-extension to the arylsulfonamide ligands increased the number of fixed waters within the binding pocket of HCA. The number of waters localized by the benzo-extended ligands cannot be attributed solely to the surface area of the ligand $-\mathbf{H}_{4} \mathbf{B T A}=448 \AA^{2}, \mathbf{F}_{4} \mathbf{B T A}=$ $483 \AA^{2}$-because $\mathbf{H}_{8} \mathbf{B T A}\left(470 \AA^{2}\right)$ has a larger surface area than $\mathbf{H}_{4} \mathbf{B T A}$, but localizes a smaller number of waters (SI).

We measured values of $\Delta H^{\circ}$ bind of $\mathbf{T A}, \mathbf{H}_{4} \mathbf{B T A}$, and $\mathbf{F}_{4} \mathbf{B T A}$ over a temperature range of 288 $-307 \mathrm{~K}$, plotted $\Delta H^{\circ}$ bind as a function of temperature, and applied a linear fit to each set of data to determine the heat capacity of binding $\left(\Delta C_{\mathrm{p}}^{\mathrm{o}}\right)$ for each ligand: $\mathbf{T A}=-13 \mathrm{cal} \mathrm{mol}^{-1} \mathrm{~K}^{-1}$, $\mathbf{H}_{4} \mathbf{B T A}=-64 \mathrm{cal} \mathrm{mol}^{-1} \mathrm{~K}^{-1}$, and $\mathbf{F}_{4} \mathbf{B T A}=-108 \mathrm{cal} \mathrm{mol}^{-1} \mathrm{~K}^{-1}$. The $\Delta C_{\mathrm{p}}^{\mathrm{o}}$ of each ligand is negative, and is compatible with our hypothesis that the interaction between the ligand and the protein is hydrophobic in nature. ${ }^{[5]}$

The difference in the heat capacity of $\mathbf{F}_{4} \mathbf{B T A}$ and $\mathbf{H}_{4} \mathbf{B T A}\left(\Delta \Delta C_{\mathrm{p}}^{0}=\Delta C_{\mathrm{p}}^{\mathrm{o}}\left(\mathbf{F}_{4} \mathbf{B T A}\right)-\Delta C_{\mathrm{p}}^{0}\right.$ $\left(\mathbf{H}_{4}\right.$ BTA $\left.)=-44 \mathrm{cal} \mathrm{mol}^{-1} \mathrm{~K}^{-1}\right)$ is much larger than the difference calculated from the buried, 
A)

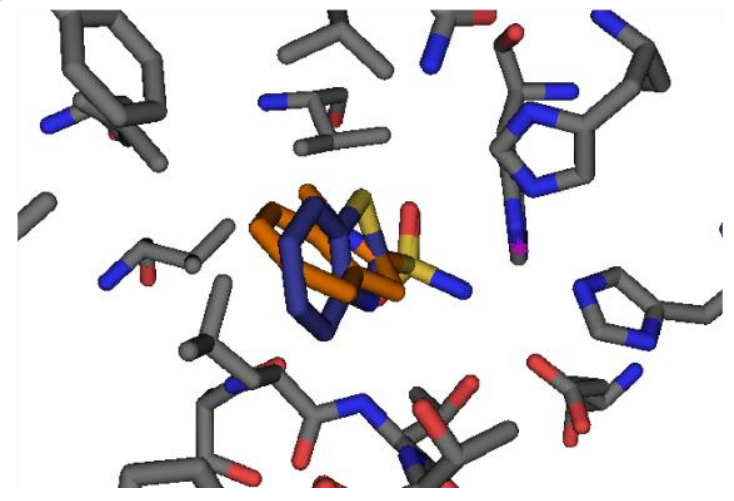

B)

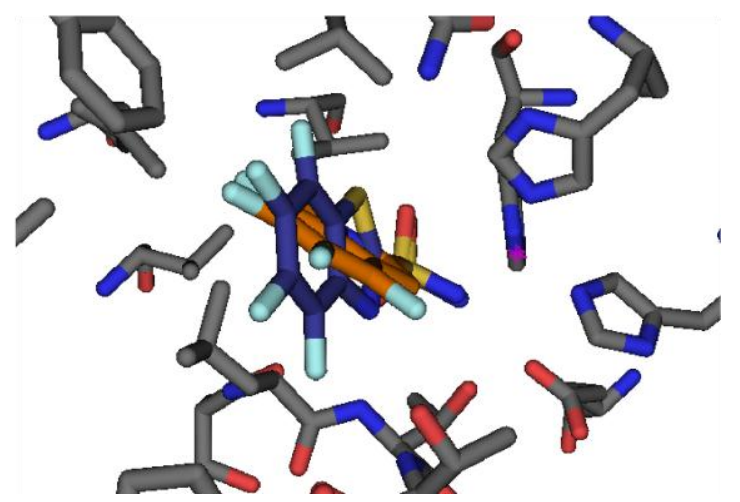

Figure 3. Side-by-side comparison the active site of HCA complexed with (F)BTA (blue) and (F)BMP (orange). A) $\mathrm{H}_{4}$ BTA and $\mathrm{H}_{4} \mathbf{B M P}$ and B) $\mathbf{F}_{4} \mathbf{B T A}$ and $\mathbf{F}_{4} \mathbf{B M P}$. 
non-polar surface area of the two ligands $\left(-19 \mathrm{cal} \mathrm{mol}^{-1} \mathrm{~K}^{-1}\right) \cdot{ }^{[5]}$ We attribute this discrepancy between the measured and predicted values of $\Delta C^{0}$ to the additional "fixed" waters observed in the crystal of $\mathbf{F}_{4}$ BTA bound to HCA (Figure 1D). The value estimated by Connelly for the ordering of a single water $\left(-9 \mathrm{cal} \mathrm{mol}^{-1} \mathrm{~K}^{-1}\right)^{[31]}$ suggests that three additional molecules of water are fixed in the binding pocket of HCA when the hydrogen atoms of $\mathbf{H}_{\mathbf{4}}$ BTA are replaced with fluorine atoms, and is consistent with the four additional waters observed in the crystal structure.

Increases in binding affinity of ligands correlates with the number of waters released from the binding pocket of $\mathrm{HCA}$, and not with the atomic composition or structure of the ligand. The calorimetry and X-ray crystallography data for the binding of benzo- and fluorobenzoextended arylsulfonamide ligands to HCA reinforce our previous conclusion: ${ }^{[3]}$ the hydrophobic effect involved in the binding of arylsulfonamide ligands to HCA is not dominated by a direct interaction between the hydrophobic surfaces of the protein and the ligand, but is a result of a more general interaction in which the non-polar ligand displaces free-energetically unfavorable waters from the binding pocket into the bulk.

The $\Delta G^{\mathrm{o}}$ bind of these ligands is independent of both the orientation of the ligand in the binding pocket of HCA, and the atoms in the benzo-extension as both ligands displace a similar number of water molecules from the binding pocket. The addition of a benzo-extension to the heterocyclic sulfonamide ligand results in a favorable increase in $\Delta H^{\mathrm{o}}$ bind; the model proposed by KT does not explain the binding of these ligands to HCA, but is compatible with their partitioning between buffer and octanol. Replacing the four hydrogen atoms of the benzoextension with fluorine atoms does result, however, in a decreased favorability of $\Delta H^{\circ}$ bind and an increased favorability of $-\mathrm{T} \Delta S^{\mathrm{o}}{ }_{\text {bind }}$. The compensation of $\Delta H^{\mathrm{o}}$ bind and $-\mathrm{T} \Delta S^{\mathrm{o}}$ bind can be 
rationalized in terms of the Coulombic interactions of each ligand with the binding pocket of HCA (i.e., the $\Delta H^{\mathrm{o}}$ bind term) and the changes in the energy of solvation (i.e., the $-\mathrm{T} \Delta S^{\mathrm{o}}$ bind term) of the benzo-extended ligand upon fluorination.

These differences in the thermodynamics of partitioning of these ligands from buffer to octanol, and from buffer to the binding pocket of HCA, support the idea that there is not a single hydrophobic effect reflecting release of water from contacting surfaces of HCA and ligand, but rather aggregated hydrophobic effects that are dependent on the structure of water in the binding pocket of HCA, and on the structure of water surrounding the ligand.

Supporting Information for this article is available on the WWW under http://dx.doi.org/10.1002/anie.XXXXXXXX.

Acknowledgements. The authors thank Drs. Jasmin Mecinovic, Ramani Ranatunge, Demetri Moustakas, Manza B.J. Atkinson, Mohammad Al-Sayah, and Shuji Fujita, and Mr. Jang Hoon Yoon, for their technical contributions. This work was supported by the National Science Foundation (CHE-1152196) and the Wyss Institute of Biologically Inspired Engineering. H.L. thanks the Deutsche Forschungsgemeinschaft (DFG) for a postdoctoral research stipend. 
Table 1. Summary of thermodynamic and structural data for the thiazole and methylpyrrole ligands

\begin{tabular}{|c|c|c|c|c|}
\hline Ligand & H4BTA & $\mathbf{F}_{4} \mathbf{B T A}$ & $\mathbf{H}_{4} \mathbf{B M P}$ & $\mathbf{F}_{4} \mathbf{B M P}$ \\
\hline$\overline{\Delta G^{0}}$ bind $\left[\mathrm{kcal} \mathrm{mol}^{-1}\right]$ & $-13.5 \pm 0.4$ & $-13.0 \pm 0.2$ & $-13.2 \pm 0.1$ & $-13.3 \pm 0.1$ \\
\hline$\Delta \Delta \mathrm{G}$ & \multicolumn{2}{|c|}{ | --- Indistinguishable --- | } & \multicolumn{2}{|c|}{ | --- Indistinguishable --- | } \\
\hline$\Delta H^{\mathrm{o}}{ }_{\text {bind }}\left[\mathrm{kcal} \mathrm{mol}^{-1}\right]$ & $-18.9 \pm 0.5$ & $-16.3 \pm 0.6$ & $-12.4 \pm 0.5$ & $-8.4 \pm 0.6$ \\
\hline$-\mathrm{T} \Delta S_{\text {bind }}^{\mathrm{o}}\left[\mathrm{kcal} \mathrm{mol}{ }^{-1}\right]$ & $5.5 \pm 0.7$ & $3.4 \pm 0.5$ & $-0.7 \pm 0.5$ & $-4.8 \pm 0.7$ \\
\hline$\Delta \Delta C_{\mathrm{p}}^{\mathrm{o}}\left[\mathrm{cal} \mathrm{mol}{ }^{-1}\right]^{\mathrm{a}}$ & |--- & -44 & \multicolumn{2}{|c|}{ Not measured } \\
\hline Fixed waters ${ }^{b}$ & 6 & 10 & 4 & 7 \\
\hline $\begin{array}{l}\Delta \text { Geometry (relative to } \\
\mathrm{H}_{4} \mathrm{BTA} \text { ) }\end{array}$ & -- & Translation $(0.7 \AA)^{\mathrm{c}}$ & Rotation $\left(27^{\circ}\right)^{\mathrm{d}}$ & Rotation $\left(31^{\circ}\right)^{d}$ \\
\hline
\end{tabular}

${ }^{\mathrm{a}} \Delta \Delta C_{\mathrm{p}}^{\mathrm{o}}=\Delta C_{\mathrm{p}}^{\mathrm{o}}\left(\mathbf{F}_{4} \mathbf{B T A}\right)-\Delta C^{\mathrm{o}} \mathrm{p}\left(\mathbf{H}_{4}\right.$ BTA $)$

${ }^{\mathrm{b}}$ Obtained from crystal structures of HCA-ligand complex.

${ }^{\mathrm{c}}$ Ligand moves in the direction of Gln 92.

${ }^{\mathrm{d}}$ Rotation along the long axis of the ligand. 
Supporting Information for this article are available on the WWW under http://dx.doi.org/10.1002/anie.XXXXXXXX.

Acknowledgements. The authors thank Dr. Jasmin Mecinovic, Dr. Ramani Ranatunge, Dr.

Demetri Moustakas, Dr. Manza Atkinson, Dr. Mohammad Al-Sayah, Dr. Shuji Fujita, and Mr.

Jang Hoon Yoon for their technical contributions. This work was supported by the National

Science Foundation (CHE-1152196) and the Wyss Institute of Biologically Inspired

Engineering. H.L. thanks the Deutsche Forschungsgemeinschaft (DFG) for a postdoctoral

research stipend. 


\section{References.}

[1] W. Blokzijl, J. B. F. N. Engberts, Angew. Chem., Int. Ed. 1993, 32, 1545.

[2] N. T. Southall, K. A. Dill, A. D. J. Haymet, J. Phys. Chem. B 2002, 106, 521.

[3] P. W. Snyder, J. Mecinovic, D. T. Moustakas, S. W. Thomas, M. Harder, E. T. Mack, M. R. Lockett, A. Heroux, W. Sherman, G. M. Whitesides, Proc. Nat. Acad. Sci., U.S.A. 2011, 108, 17889.

[4] C. Tanford, Proc. Nat. Acad. Sci., U.S.A. 1979, 76, 4175.

[5] N. V. Prabhu, K. A. Sharp, Ann. Rev. Phys. Chem. 2005, 56, 521.

[6] W. Kauzmann, Ann. Rev. Phys. Chem. 1957, 8, 413.

[7] W. P. Jencks, Catalysis in Chemistry and Enzymology, McGraw-Hill, New York, New York, 1969.

[8] S. W. Homans, Drug Discov. Today 2007, 12, 534.

[9] J. Mecinovic, P. W. Snyder, K. A. Mirica, S. Bai, E. T. Mack, R. L. Kwant, D. T. Moustakas, A. Heroux, G. M. Whitesides, J. Am. Chem. Soc. 2011, 133, 14017.

[10] B. J. Berne, J. D. Weeks, R. Zhou, Ann. Rev. Phys. Chem. 2009, 60, 85.

[11] K. Lum, D. Chandler, J. D. Weeks, J. Phys. Chem. B 1999, 103, 4570.

[12] R. Chakrabarti, A. Klibanov, R. Friesner, Proc. Nat. Acad. Sci., U.S.A. 2005, 102, 10153.

[13] R. Abel, T. Young, R. Farid, B. Berne, R. Friesner, J. Am. Chem. Soc. 2008, 130, 2817.

[14] A. Biela, N. N. Nasief, M. Betz, A. Heine, D. Hangauer, G. Klebe, Angew. Chem., Int. Ed. 2013, 52, 1.

[15] T. S. G. Olsson, J. E. Ladbury, W. R. Pitt, Protein Sci. 2011, 20, 1607.

[16] T. S. G. Olsson, M. A. Williams, W. R. Pitt, J. E. Ladbury, J. Mol. Biol. 2008, 384, 1002.

[17] R. U. Lemieux, Acc. Chem. Res. 1996, 29, 373.

[18] N. Giovambattista, C. F. Lopez, P. J. Rossky, P. G. Debenedetti, Proc. Nat. Acad. Sci., U.S.A. 2008, 105, 2274.

[19] P. J. Rossky, M. Karplus, J. Am. Chem. Soc. 1979, 101, 1913.

[20] M. C. Chervenak, E. J. Toone, J. Am. Chem. Soc. 1994, 116, 10533.

[21] T. G. Oas, E. J. Toone, Adv. Biophys. Chem. 1997, 6, 1.

[22] J. D. Dunitz, ChemBioChem 2004, 5, 614.

[23] M. Salwiczek, E. K. Nyakatura, U. I. M. Gerling, S. Ye, B. Koksch, Chem. Soc. Rev. 2012, 41, 2135.

[24] J. C. Biffinger, H. W. Kim, S. G. DiMagno, ChemBioChem 2004, 5, 622.

[25] A. Bondi, J. Phys. Chem. 1964, 68, 441.

[26] V. M. Krishnamurthy, G. K. Kaufman, A. R. Urbach, I. Gitlin, K. L. Gudiksen, D. B. Weibel, G. M. Whitesides, Chem. Rev. 2008, 108, 946.

[27] E. A. Meyer, R. K. Castellano, F. Diederich, Angew. Chem., Int. Ed. 2003, 42, 1210.

[28] P. D. Lyne, M. L. Lamb, J. C. Saeh, J. Med. Chem. 2006, 49, 4805.

[29] E. Freire, Drug Discov. Today 2008, 13, 869.

[30] R. Abel, N. K. Salam, J. Shelley, R. Farid, R. A. Friesner, W. Sherman, ChemMedChem 2011, 6, 1049.

[31] P. R. Connelly, Structure-Based Drug Design: Thermodynamics, Modeling and Strategy, Springer, Berlin, 1997. 


\title{
SUPPORTING INFORMATION
}

\section{The Binding of Benzoarylsulfonamide Ligands to Human Carbonic Anhydrase is Insensitive to Formal Fluorination of the Ligands}

\author{
Heiko Lange, ${ }^{\mathrm{a}, \dagger}$ Matthew R. Lockett, ${ }^{\mathrm{a}, \dagger}$ Benjamin Breiten, ${ }^{\mathrm{a}}$ Annie Heroux, ${ }^{\mathrm{b}}$ Woody Sherman, ${ }^{\mathrm{c}}$

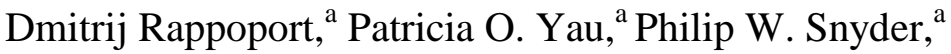 \\ George M. Whitesides ${ }^{\mathrm{a}, \mathrm{d}, *}$
}

\footnotetext{
${ }^{a}$ Department of Chemistry and Chemical Biology, Harvard University 12 Oxford Street, Cambridge, MA 02138

${ }^{b}$ National Synchrotron Light Source, Brookhaven National Laboratory 725 Brookhaven Avenue, Upton, NY 11973-5000

${ }^{c}$ Schrödinger Inc., 120 West $45^{\text {th }}$ Street, New York, NY 10036-4041

${ }^{d}$ Wyss Institute for Biologically Inspired Engineering, Harvard University 60 Oxford Street, Cambridge, MA 02138
} 


\section{Expression and Purification of Human Carbonic Anhydrase}

We chose human carbonic anhydrase II (HCA, E.C. 4.2.1.1) as a model protein to study the hydrophobic effect in protein-ligand binding, because HCA: i) is well-characterized structurally, ${ }^{[1]}$ and has a binding pocket comprised of a distinct "hydrophobic wall" and a distinct "hydrophilic wall"; [1] ii) is structurally rigid, and retains its secondary and tertiary structure upon binding of a ligand $;^{[1,2]}$ iii) can be expressed in E. coli in the quantities necessary for calorimetry experiments and X-ray crystallography; iv) crystallizes readily, and the conditions for growing crystals, reproducibly, are known. ${ }^{[3]}$

We expressed HCA in BL21(DE3)pLysS competent cells (Promega, Madison, WI), transformed with a pACA plasmid containing the HCA gene, ${ }^{[4][5]}$ according to the procedures published by Fierke and coworkers. ${ }^{[5]}$ After expression, the cultures of E. coli were pelleted (20 $\min , 10,000 \times g, 4{ }^{\circ} \mathrm{C}$ ), flash frozen under liquid nitrogen, and stored at $-80{ }^{\circ} \mathrm{C}$ until needed.

We lysed the E. coli with BPER protein extraction buffer (Thermo Scientific) augmented with: $\mathrm{MgSO}_{4}(1 \mathrm{mM}), N$ - -tosyl-L-arginine methyl ester (TAME, $\left.1 \mathrm{mM}\right)$, $\operatorname{tris}(2-$ carboxyethyl)phosphine (TCEP, $3 \mathrm{mM}), \mathrm{ZnSO}_{4}(2.5 \mathrm{mM})$, phenylmethanesulfonyl fluoride (PMSF, $1 \mu \mathrm{M})$, lysozyme $(0.125 \mu \mathrm{g} / \mathrm{mL})$, and DNase I (10 U / mL). The HCA was precipitated from the cellular lysate with ammonium sulfate $(60 \% \mathrm{v} / \mathrm{v}$ with a solution of saturated ammonium sulfate), and then dialyzed into Tris-SO $\mathrm{SO}_{4}$ buffer $(50 \mathrm{mM}, \mathrm{pH}=8.0)$ containing $\mathrm{ZnSO}_{4}(200 \mu \mathrm{M})$ and TCEP $(200 \mu \mathrm{M})$. The dialyzed protein was further purified on an AKTA purifier (GE Healthcare) with: i) anion exchange chromatography with Q Sepharose Fast Flow resin (Sigma Aldrich); and ii) size exclusion chromatography with SuperDex 75 resin (GE Healthcare). We used Tris-SO $\mathrm{SO}_{4}$ buffer $(50 \mathrm{mM}, \mathrm{pH}=8.0)$ containing $\mathrm{ZnSO}_{4}(200 \mu \mathrm{M})$ and TCEP $(200 \mu \mathrm{M})$ for all chromatographic separations. 


\section{Synthesis of the Heteroarylsulfonamide Ligands}

We synthesized the benzo- and fluorobenzo-extended ligands from commercially available starting materials, which we used without further purification (Sigma Aldrich, Alfa Aesar, TCI, and 3B Scientific Corporation). We characterized the final product of each synthesis with ${ }^{1} \mathrm{H}$ and ${ }^{19} \mathrm{~F}$ NMR spectroscopy, and GC-MS (EI). We measured ${ }^{1} \mathrm{H}$ and ${ }^{19} \mathrm{~F}$ spectra on a 300 or $400 \mathrm{MHz}$ instrument, and report the chemical shifts (in ppm) relative to tetramethylsilane for ${ }^{1} \mathrm{H}$ NMR spectra, and relative to trichloro-fluoromethane for ${ }^{19} \mathrm{~F}$ NMR spectra. Coupling constants $(J)$ are given in $\mathrm{Hz}$, and the apparent resonance multiplicities are abbreviated with (b)s ((broad) singlet), $\mathrm{d}$ (doublet), $\mathrm{t}$ (triplet), and $\mathrm{m}$ (multiplet). We measured the mass of each compound with an Agilent GC/MSD 5975A inert with a Triple-Axis Detector, controlled via Agilent GC ChemStation Software (version E.02.00.493), containing a HP 5MS column (5\% diphenyl 95\% dimethylpolysiloxane, $30 \mathrm{~m} \times 0.25 \mathrm{~mm})$.

We synthesized the benzo-extended ligands according to previously published synthetic procedures: benzo[b]thiophene-2-sulfonamide $\left(\mathbf{H}_{\mathbf{4}} \mathbf{B T}\right),{ }^{[6]}$ benzo $[d]$ thiazole-2-sulfonamide $\left(\mathbf{H}_{4} \mathbf{B T A}\right),{ }^{[6]} 1 H$-indole-2-sulfonamide $\left(\mathbf{H}_{4} \mathbf{B P}\right),{ }^{[7]} 1$-methyl-1H-indole-2-sulfonamide $\left(\mathbf{H}_{4} \mathbf{M B P}\right),{ }^{[8]} 4,5,6,7$-tetrahydrobenzo $[b]$ thiophene-2-sulfonamide $\left(\mathbf{H}_{8} \mathbf{B T}\right),{ }^{[9]}$ and 4,5,6,7tetrahydrobenzo $[d]$ thiazole-2-sulfonamide $\left(\mathbf{H}_{8} \mathbf{B T A}\right) \cdot{ }^{[10]}$ We stored all ligands under argon or nitrogen at room temperature.

General Synthetic Procedure for Fluorobenzo-extended Ligands. If not stated otherwise, the fluorobenzo-extended ligands were synthesized following a general synthetic procedure (GP) developed by Chern et al. ${ }^{[6]}$ The starting material (typically $10 \mathrm{mmol}, 1$ equiv.) was dissolved in dry tetrahydrofuran (THF) under an argon atmosphere, cooled to $-78^{\circ} \mathrm{C}$, and reacted with a 1.6 M solution of $n$-butyllithium in hexanes (1.1 equiv.). The reaction mixture was stirred for 1 hour, 
and allowed to warm to ca. $0^{\circ} \mathrm{C}$ before the intermediate aryl lithium species was quenched with dry gaseous sulfur dioxide. Sulfur dioxide was blown over the surface of the reaction solution for approximately five minutes to exchange the atmosphere in the flask, and the flask re-sealed with a balloon filled with gaseous sulfur dioxide. The reaction mixture was stirred for an additional hour, and the reaction mixture was allowed to warm to room temperature. Argon was then bubbled through the reaction suspension to remove the excess of sulfur dioxide, and the resulting slurry was concentrated in vacuo to yield the lithium benzoaryl-2-sulfinate as a pasty solid.

The crude lithium sulfinates were re-dissolved in aqueous sodium acetate, hydroxylamine- $O$ sulfonic acid (2.5 equiv.) was added at $0^{\circ} \mathrm{C}$, and the mixture stirred overnight at room temperature. The precipitate was isolated by filtration, washed with cold water, and the fluorobenzo-extended ligands recrystallized.

4,5,6,7-tetrafluorobenzo[b]thiophene-2-sulfonamide $\left(F_{4} B T\right)$. $\mathbf{F}_{4} \mathrm{BT}$ was synthesized, according to the general procedure (GP) outlined above, from 4,5,6,7tetrafluorobenzo[b]thiophene, which was prepared from 4,5,6,7-tetrafluorobenzo[b]thiophen-2carboxylic acid ${ }^{[11]}$ using a copper-catalyzed decarboxylation described previously. ${ }^{[12]}$

${ }^{1} \mathrm{H}$ NMR $\left(300 \mathrm{MHz}\right.$, DMSO- $\left.d_{6}\right) \delta 8.17$ (bs, 2H), 7.54 (s, 1H); ${ }^{19}$ F NMR (282 MHz, DMSO$\left.d_{6}\right) \delta-137.5(\mathrm{dd}, J=14.4,21.4),-147.0(\mathrm{dd}, J=14.8,20.8),-155.7(\mathrm{t}, J=21.3),-156.4(\mathrm{t}, J=$ 20.8); GC-MS (EI, $70 \mathrm{eV}): \mathrm{m} / \mathrm{z} 284.9\left(\mathrm{M}^{+}, 100 \%\right) @ t_{\mathrm{R}} 21.8 \mathrm{~min}$.

4,5,6,7-tetrafluorobenzo[d]thiazole-2-sulfonamide $\left(F_{4} B T A\right)$. F $_{4}$ BTA was prepared from 2,3,4,5,6-pentafluoroaniline, which was prepared from 4,5,6,7-tetrafluorobenzo[d]thiazole-2thione. ${ }^{[13]}$ The thione was reacted with an aqueous solution of ammonia in the presence of sodium hydroxide and sodium hypochlorite to yield the intermediate $S$ - 
(perfluorobenzo[d]thiazol-2-yl)thiohydroxylamine. ${ }^{[14]}$ The latter was isolated and treated with hydrogen peroxide solution to furnish $\mathbf{F}_{\mathbf{4}} \mathbf{B T A}$ after re-crystallization.

${ }^{1} \mathrm{H}$ NMR $\left(300 \mathrm{MHz}\right.$, DMSO- $\left.d_{6}\right) \delta 8.68(\mathrm{bs}, 2 \mathrm{H}) ;{ }^{19} \mathrm{~F}$ NMR $\left(282 \mathrm{MHz}\right.$, DMSO- $\left.d_{6}\right) \delta-137.5$ (dd, $J=14.4,21.4),-147.0(\mathrm{dd}, J=14.8,20.8),-155.7(\mathrm{t}, J=21.3),-156.4(\mathrm{t}$, $J=20.8)$; GC-MS (EI, $70 \mathrm{eV}): \mathrm{m} / \mathrm{z} 268.9\left(\left[\mathrm{M}-\mathrm{H}_{2} \mathrm{O}\right]^{+}, 100 \%\right) @ t_{\mathrm{R}} 13.0 \mathrm{~min}$.

4,5,6,7-tetrafluorobenzo[b]-1H-pyrrole-2-sulfonamide $\left(F_{4} B P\right) . \mathbf{F}_{4} \mathbf{B P}$ was synthesized from 4,5,6,7-tetrafluoro- $1 H$-indole according to the $\mathbf{G P}$ outlined above, after the indole-nitrogen was protected with a benzoyl group according to standard protocols. ${ }^{[6]}$ The final product was deprotected according to standard protocols. ${ }^{[6]}$

${ }^{1} \mathrm{H}$ NMR (300 MHz, DMSO- $\left.d_{6}\right) \delta 7.81$ (bs, 2H), 7.10 (s, $\left.1 \mathrm{H}\right), 3.35$ (bs, ca.1H); ${ }^{19}$ F NMR $\left(282 \mathrm{MHz}\right.$, DMSO- $\left.d_{6}\right) \delta-149.4(\mathrm{dd}, J=17.2,21.0),-157.6(\mathrm{dd}, J=17.1,20.3),-163.5(\mathrm{t}, J=$ 20.4), -169.0 (dt, $J=21.0,3.4)$; GC-MS (EI, $70 \mathrm{eV}): \mathrm{m} / \mathrm{z} 268.0\left(\mathrm{M}^{+}, 100 \%\right) @ t_{\mathrm{R}} 21.2 \mathrm{~min}$.

\section{4,5,6,7-tetrafluorobenzo[b]-N-methyl-pyrrole-2-sulfonamide $\left(F_{4} M B P\right) . \mathrm{F}_{4} \mathrm{MBP}$ was} synthesized from 4,5,6,7-tetrafluoro- $N$-methyl-indole, according to the $\mathbf{G P}$ outlined above, which was obtained by the methylation of 4,5,6,7-tetrafluoro- $1 \mathrm{H}$-indole with methyl iodide in the presence of sodium hydride in dry THF. ${ }^{[6]}$

${ }^{1} \mathrm{H}$ NMR $\left(300 \mathrm{MHz}\right.$, DMSO-d $\left.d_{6}\right) \delta 8.14$ (bs, 2H), 7.10 (s, 1H), 3.31 (s, 3H); ${ }^{19} \mathrm{~F}$ NMR $(282$ MHz, DMSO- $\left.d_{6}\right) \delta-149.6(\mathrm{dd}, J=16.8,20.9),-161.9(\mathrm{t}(\mathrm{dd}), J=20.8),-162.9(\mathrm{t}$, $J=20.7),-169.0(\mathrm{dt}, J=21.1,3.8)$; GC-MS (EI, $70 \mathrm{eV}): \mathrm{m} / \mathrm{z} 282.0\left(\mathrm{M}^{+}, 100 \%\right) @ t_{\mathrm{R}} 20.3 \mathrm{~min}$. 


\section{Physiochemical Characterization of the Heteroarylsulfonamide Ligands}

We summarize the physico-chemical data collected for each sulfonamide ligand in Table S1, and discuss the procedures in detail below.

Determination of $p K_{a}$. The $\mathrm{p} K_{\mathrm{a}}$ of T, TA, $\mathbf{H}_{4} \mathrm{BT}, \mathrm{H}_{8} \mathrm{BT}$, and $\mathrm{H}_{4} \mathrm{BTA}$ (Figure S1) were

determined previously. ${ }^{[2]}$ We used the same procedure to determine the $\mathrm{p} K_{\mathrm{a}}$ of the fluorobenzoextended ligands: a solution of the ligand (20 mM in DMSO) was added to a buffered solution (10 mM, ranging from $\mathrm{pH} 1$ to $\mathrm{pH} 13$ in 0.5 increments of $\mathrm{pH}$ ) in a cuvette, and a UV-VIS spectrum obtained.

Determination of $\Delta \boldsymbol{H}^{o}{ }_{\text {ion }}$. We could not measure the $\Delta H^{\mathrm{o}}$ ion of the fluorobenzo-extended ligands directly with calorimetry due to their low solubility. To approximate values of $\Delta H^{\mathrm{o}}$ ion, we correlated the chemical shift of the proton in the sulfonamide group, measured with ${ }^{1} \mathrm{H}$ NMR spectroscopy, with the chemical shift of the proton in the sulfonamide group of known heteroarylsulfonamide ligands (Figure S1) - namely thiophene-2-sulfonamide (T), benzothiophene-2-sulfonamide $\left(\mathbf{H}_{4} \mathbf{B T}\right)$, thiazole-2-sulfonamide (TA), benzothiazole-2sulfonamide ( $\mathbf{H}_{4}$ BTA), furane-2-sulfonamide (F), benzofurane-2-sulfonamide $\left(\mathbf{H}_{4} \mathbf{B F}\right)$, imidazole-2-sulfonamide (I), benzoimidazole-2-sulfonamide $\left(\mathbf{H}_{4} \mathbf{B I}\right)$, benzopyrrole-2sulfonamide $\left(\mathbf{H}_{4} \mathbf{B P}\right)$.

Partitioning experiments. We measured the equilibrium constant of partitioning, between sodium phosphate buffer $(10 \mathrm{mM}, \mathrm{pH}=7.6)$ and octanol, for each of the benzo- and fluorobenzoextended ligands using the shake-flask method described previously. ${ }^{[2]}$

Solution calorimetry. We followed the procedure reported previously, ${ }^{[2]}$ and measured the heat of dissolution for solid samples of each ligand (5-10 mg) with a TAMIII calorimeter (TA Instruments). 
Table S1. Physico-chemical properties of the heteroarylsulfonamide ligands, and the Zn(II)bound-water form of HCA II (HCA-Zn(II)- $\mathrm{OH}_{2}^{+}$), used in this study.

\begin{tabular}{|c|c|c|c|c|c|c|}
\hline $\begin{array}{l}\text { system } \\
\text { ligand }\end{array}$ & $\begin{array}{c}\text { SASA } \\
{\left[\AA^{2}\right]}\end{array}$ & $\mathrm{p} K_{\mathrm{a}}$ & $\begin{array}{c}\Delta H^{\circ}{ }_{\text {ion }} \\
{\left[\mathrm{kcal}^{-1}\right.} \\
\left.\mathrm{mol}^{-1}\right]^{\mathrm{a}}\end{array}$ & $\log P^{\mathrm{b}}$ & $\begin{array}{c}\Delta G^{\circ} \text { ow } \\
{[\mathrm{kcal}} \\
\left.\mathrm{mol}^{-1}\right]\end{array}$ & $\begin{array}{c}\Delta G^{\circ} \text { OW } \\
\text { per } \AA^{2} \\
{\left[\mathrm{cal} \mathrm{mol}^{-1}\right.} \\
\left.\AA^{-2}\right]\end{array}$ \\
\hline \multicolumn{7}{|l|}{ thiophene } \\
\hline $\mathbf{T}$ & 301 & 9.6 & 8.4 & 1.62 & $0.8 \pm 0.04$ & 2.7 \\
\hline $\mathbf{H}_{4} \mathrm{BT}$ & 369 & 9.5 & 8.1 & 0.76 & $1.6 \pm 0.1$ & 4.3 \\
\hline $\mathbf{F}_{4} \mathbf{B T}$ & 380 & 8.6 & 7.8 & -0.44 & $2.0 \pm 0.3$ & 5.3 \\
\hline $\mathrm{H}_{8} \mathrm{BT}$ & 394 & $9.8^{c}$ & 8.5 & n.d. & n.d. & n.d. \\
\hline \multicolumn{7}{|l|}{ thiazole } \\
\hline TA & 296 & 8.4 & 7.7 & 1.46 & $-0.8 \pm 0.03$ & -2.7 \\
\hline $\mathrm{H}_{4}$ BTA & 364 & 8.2 & 7.4 & -0.25 & $1.3 \pm 0.3$ & 3.6 \\
\hline $\mathbf{F}_{4} \mathbf{B T A}$ & 379 & 7.9 & 7.2 & -1.33 & $2.5 \pm 0.1$ & 6.6 \\
\hline $\mathrm{H}_{8}$ BTA & 391 & n.d. & n.d. & n.d. & n.d. & n.d. \\
\hline \multicolumn{7}{|l|}{ pyrrole } \\
\hline $\mathrm{H}_{4} \mathrm{BP}$ & 366 & 9.8 & 8.5 & 1.12 & $1.5 \pm 0.2$ & 4.1 \\
\hline $\mathbf{F}_{4} \mathbf{B P}$ & 377 & 9.4 & 8.2 & 0.11 & $2.3 \pm 0.1$ & 6.1 \\
\hline \multicolumn{7}{|l|}{$N$-methyl pyrrole } \\
\hline $\mathrm{H}_{4} \mathrm{MBP}$ & 384 & 9.4 & 8.2 & 0.65 & $1.6 \pm 0.3$ & 4.1 \\
\hline $\mathrm{F}_{4} \mathrm{MBP}$ & 402 & 8.8 & 7.8 & -0.12 & $1.8 \pm 0.6$ & 4.5 \\
\hline \multicolumn{7}{|l|}{ protein } \\
\hline $\mathrm{HCA}-\mathrm{Zn}(\mathrm{II})-\mathrm{OH}_{2}{ }^{+\mathrm{d}}$ & n.d. & $(6.9)$ & 6.9 & --- & --- & --- \\
\hline
\end{tabular}

a) NMR experiments were performed in DMSO- $d_{6}$ at $25^{\circ} \mathrm{C}$.

b) Calculated via $\log P=\log D+\log \left(1+10^{\mathrm{pKa}-\mathrm{pH}}\right)$.

c) Determined previously by Snyder et al. ${ }^{[2]}$

d) Values estimated according to the literature. ${ }^{[1]}$ 


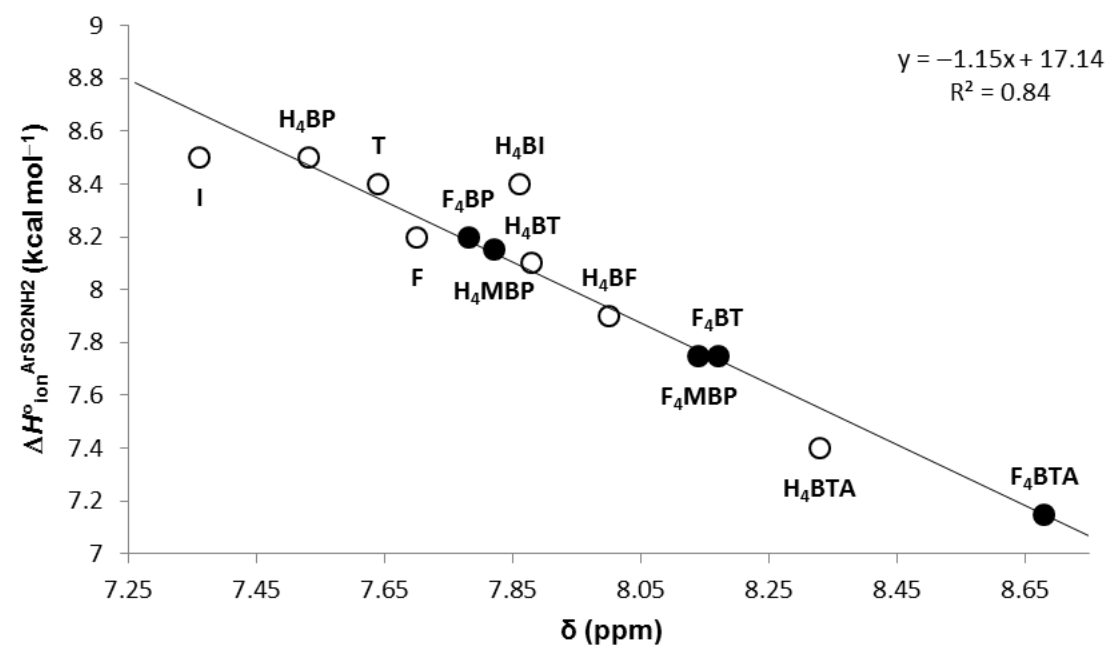

Figure S1. NMR-based approximation of values of $\Delta H^{\circ}$ ion for the fluorobenzo-extended ligands. The solid black circles represent an independently measured value of $\Delta H^{\circ}$ ion for the fluorobenzoextended ligands. The hollow circles represent an independently measured value of $\Delta H^{\circ}$ ion from compounds for which $\Delta H^{\circ}$ ion had been independently determined, and reported ${ }^{[2]}: \mathbf{I}-$ imidazole- $^{\circ}$ 2-sulfonamide, $\mathbf{H}_{\mathbf{4}} \mathbf{B P}$ - benzo[b]pyrrole-2-sulfonamide, $\mathbf{T}$ - thiophene-2-sulfonamide, $\mathbf{F}$ furane-2-sulfonamide, $\mathbf{H}_{\mathbf{4}} \mathbf{B T}$ - benzo[b]thiophene-2-sulfonamide, $\mathbf{H}_{\mathbf{4}} \mathbf{B F}$ - benzo[ $\left.b\right]$ furane-2sulfonamide, $\mathbf{H}_{\mathbf{4}}$ BTA - benzo[ $[d]$ thiazole-2-sulfonamide We correlated the chemical shift of the sulfonamide proton to obtain the linear curves displayed. 


\section{Isothermal Titration Calorimetry}

We conducted all ITC experiments on an Auto VP-ITC instrument (Microcal). In each titration experiment, 19 injections of ligand $(7.8 \mu \mathrm{L}, 100 \mu \mathrm{M})$ were introduced into the calorimeter cell, which contained HCA $(1.6 \mathrm{~mL}, 100 \mu \mathrm{M})$, and the heat of binding $\left(\Delta H^{\mathrm{o}}{ }_{\text {bind }}\right)$ was recorded. We used sodium phosphate buffer $(10 \mathrm{mM}, \mathrm{pH}=7.60)$ for all experiments.

The raw data were analyzed using the Origin software package, and the free energy of binding $\left(\Delta G^{\mathrm{o}}{ }_{\text {bind }}\right)$ and entropy of binding ( $\left.-\mathrm{T} \Delta S^{\mathrm{o}}{ }_{\text {bind }}\right)$ estimated with a nonlinear, single-binding site model. Values of $K_{\mathrm{a}}, \Delta G^{\mathrm{o}}$ bind, $\Delta H^{\mathrm{o}}{ }_{\text {bind }}$, and $-\mathrm{T} \Delta S^{\mathrm{o}}$ bind are the average of at least seven experiments and the uncertainties are one standard deviation from the mean.

pK $K_{\boldsymbol{a}}$-correction of observed ITC data: We corrected the $K_{\mathrm{a}}$ of each arylsulfonamide ligandto reflect the binding of the arylsulfonamide anion $\left(\mathrm{ArSO}_{2} \mathrm{NH}^{-}\right)$to the zinc-bound water form of HCA $\left(\mathrm{HCA}-\mathrm{Zn}^{\mathrm{II}}-\mathrm{OH}_{2}{ }^{+}\right)$- using a previously reported method, ${ }^{[15]}$ which is explained in detail by Snyder et al ${ }^{[2]}$ Table $\mathrm{S} 2$ lists the observed, and the $\mathrm{p} K_{\mathrm{a}}$-corrected values of $\Delta G^{\mathrm{o}}$ bind, $\Delta H^{\mathrm{o}}$ bind, and $-\mathrm{T} \Delta S^{\mathrm{o}}{ }_{\text {bind }}$ for the sulfonamide ligands investigated in this study. Figure $\mathrm{S} 2$ shows $\Delta G^{\circ}$ bind, $\Delta H^{\circ}{ }_{\text {bind }}$, and $-\mathrm{T} \Delta S_{\text {bind }}^{\circ}$ as function of SASA for each ligand. 
Table S2. Observed and $\mathrm{p} K_{\mathrm{a}}$-corrected thermodynamic parameters for free energy of binding ( $\left.\Delta G^{\circ}{ }_{\text {bind }}\right)$, enthalpy of binding $\left(\Delta H^{\circ}\right.$ bind $)$, and entropy of binding (-T $\Delta S^{\circ}$ bind $)$ for the anion of each heteroarylsulfonamide ligand to HCA II.

\begin{tabular}{|c|c|c|c|c|c|c|c|c|}
\hline \multirow[t]{2}{*}{ Ligand } & \multirow[t]{2}{*}{$\mathrm{N}^{\mathrm{a}}$} & \multirow{2}{*}{$\begin{array}{l}\text { SASA } \\
\left(\AA^{2}\right)\end{array}$} & \multicolumn{2}{|c|}{$\begin{array}{l}\Delta G_{\text {bind }}^{\circ} \\
\left(\mathrm{kcal} \mathrm{mol}^{-1}\right)\end{array}$} & \multicolumn{2}{|c|}{$\begin{array}{l}\Delta H^{\circ}{ }_{\text {bind }} \\
\left(\mathrm{kcal} \mathrm{mol}^{-1}\right)\end{array}$} & \multicolumn{2}{|c|}{$\begin{array}{l}-\mathrm{T} \Delta S_{\text {bind }}^{\circ} \\
\left(\mathrm{kcal} \mathrm{mol}^{-1}\right)\end{array}$} \\
\hline & & & observed & corrected $^{b}$ & observed & corrected $^{\mathrm{b}}$ & observed & corrected $^{\mathrm{b}}$ \\
\hline \multicolumn{9}{|l|}{ thiophene } \\
\hline $\mathbf{T}$ & 6 & 303 & $-9.0 \pm 0.1$ & $-12.8 \pm 0.1$ & $-9.4 \pm 0.4$ & $-11.9 \pm 0.4$ & $0.4 \pm 0.5$ & $-0.9 \pm 0.5$ \\
\hline $\mathbf{H}_{4} \mathrm{BT}$ & 9 & 369 & $-11.2 \pm 0.2$ & $-14.4 \pm 0.2$ & $-13.7 \pm 0.4$ & $-15.7 \pm 0.4$ & $2.5 \pm 0.3$ & $1.3 \pm 0.3$ \\
\hline $\mathrm{F}_{4} \mathrm{BT}$ & 9 & 380 & $-11.3 \pm 0.2$ & $-13.9 \pm 0.2$ & $-13.2 \pm 0.6$ & $-14.5 \pm 0.6$ & $1.9 \pm 0.5$ & $0.7 \pm 0.5$ \\
\hline $\mathrm{H}_{8} \mathrm{BT}$ & 7 & 394 & $-10.5 \pm 0.1$ & $-14.7 \pm 0.1$ & $-11.6 \pm 0.1$ & $-14.4 \pm 0.1$ & $1.1 \pm 0.02$ & $0.3 \pm 0.1$ \\
\hline \multicolumn{9}{|l|}{ thiazole } \\
\hline $\mathbf{T A}$ & 7 & 296 & $-10.0 \pm 0.1$ & $-12.3 \pm 0.1$ & $-13.9 \pm 0.2$ & $-14.7 \pm 0.2$ & $-3.8 \pm 0.3$ & $-2.5 \pm 0.3$ \\
\hline $\mathrm{H}_{4}$ BTA & 9 & 364 & $-11.4 \pm 0.3$ & $-13.5 \pm 0.3$ & $-18.6 \pm 0.6$ & $-18.8 \pm 0.6$ & $-7.1 \pm 0.8$ & $-5.3 \pm 0.8$ \\
\hline $\mathbf{F}_{4} \mathbf{B T A}$ & 9 & 379 & $-11.3 \pm 0.2$ & $-13.0 \pm 0.2$ & $-17.3 \pm 0.6$ & $-16.3 \pm 0.6$ & $-6.0 \pm 0.5$ & $-3.4 \pm 0.5$ \\
\hline $\mathrm{H}_{8}$ BTA & n.d. & 391 & n.d. & n.d. & n.d. & n.d. & n.d. & n.d. \\
\hline \multicolumn{9}{|l|}{ pyrrole } \\
\hline $\mathbf{B P}$ & 12 & 366 & $-10.3 \pm 0.1$ & $-14.2 \pm 0.1$ & $-10.8 \pm 1.2$ & $-13.4 \pm 1.2$ & $-0.6 \pm 1.2$ & $0.9 \pm 1.2$ \\
\hline $\mathbf{F}_{4} \mathbf{B P}$ & 13 & 377 & $-10.3 \pm 0.2$ & $-13.7 \pm 0.2$ & $-8.6 \pm 1.2$ & $-10.7 \pm 1.2$ & $1.8 \pm 1.0$ & $3.0 \pm 1.0$ \\
\hline \multicolumn{9}{|c|}{$N$-methyl pyrrole } \\
\hline $\mathrm{H}_{4} \mathrm{MBP}$ & 9 & 384 & $-9.9 \pm 0.1$ & $-13.2 \pm 0.1$ & $-10.4 \pm 0.5$ & $-12.4 \pm 0.5$ & $-0.5 \pm 0.5$ & $-0.7 \pm 0.5$ \\
\hline $\mathbf{F}_{4} \mathbf{M B P}$ & 6 & 402 & $-10.6 \pm 0.1$ & $-13.3 \pm 0.1$ & $-6.9 \pm 0.8$ & $-8.5 \pm 0.8$ & $3.7 \pm 0.8$ & $4.8 \pm 0.8$ \\
\hline
\end{tabular}

a Number of experiments used for analyses.

b Corrected for the $\mathrm{p} K_{\mathrm{a}}$-values determined as described above. 

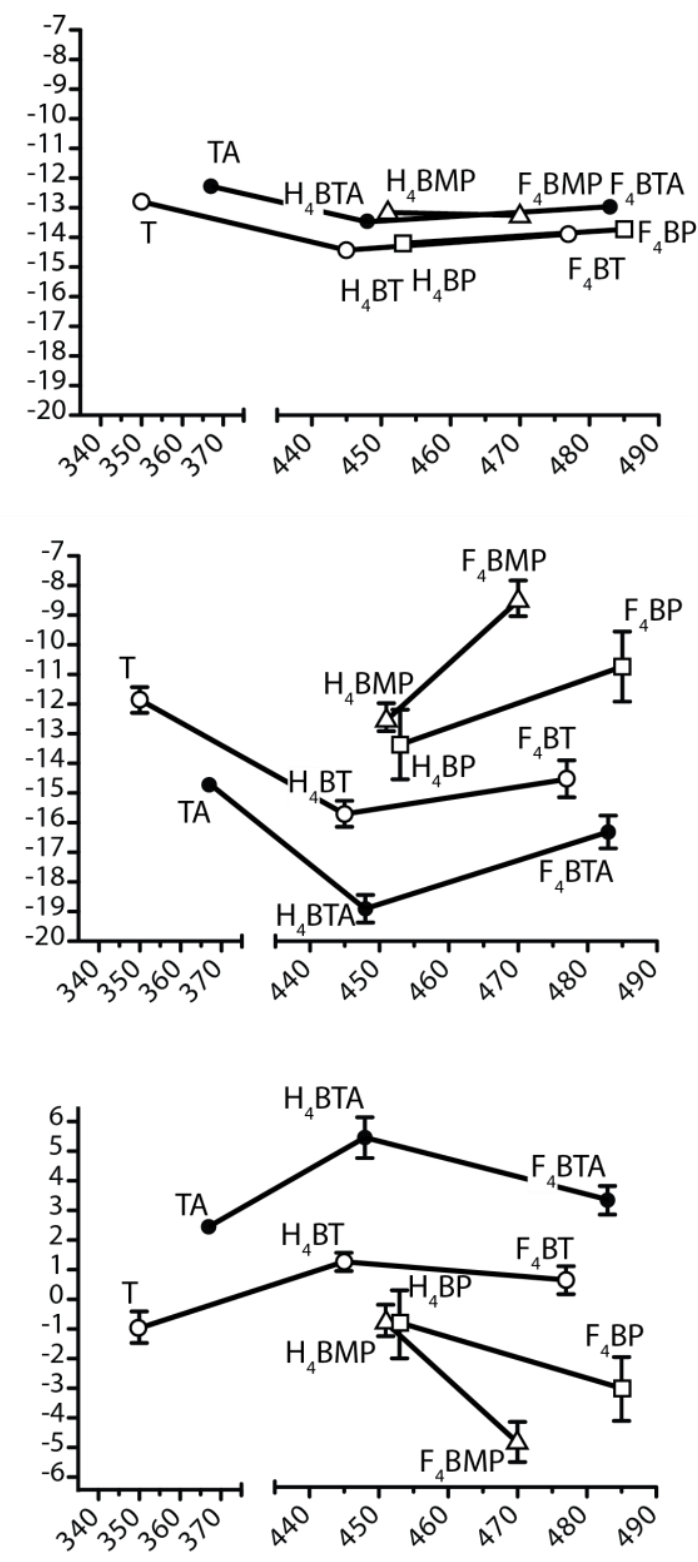

Solvent-accessible surface area $\left(\AA^{2}\right)$

Figure S2. The thermodynamics of binding (i.e., $\Delta G^{\mathrm{o}}$ bind, $\Delta H^{\mathrm{o}}$ bind, and $-\mathrm{T} \Delta S^{\mathrm{o}}$ bind ) of the anions of heteroarylsulfonamide ligands to HCA as a function of the difference in solvent-accessible surface area between the bound and unbound states of the ligand $\left(\triangle S A S A_{\text {unbound }}=\triangle S A S A_{\text {bound }}+\right.$ $\left.\triangle S A S A_{\text {protein }}-\triangle S A S A_{\text {complex }}\right)$. Each datum represents the average values of at least seven independent measurements (the error bars represent one standard deviation from the mean). 


\section{Decomposition of the Free Energy of Binding Calculations}

We calculated the binding energies of $\mathbf{H}_{\mathbf{4}} \mathbf{B T A}$ and $\mathbf{F}_{\mathbf{4}} \mathbf{B T A}$ using the MM-GBSA method ${ }^{[16]}$ (as implemented in Prime ${ }^{[17,18]}$ ). We prepared the initial crystal structure coordinates for the F 4 BTA-HCA complex with the Protein Preparation Wizard in Maestro (using the $\mathbf{H}_{4} \mathbf{B T A}-\mathrm{HCA}$ complex, PDB code 3S73). The Prime MM-GBSA calculations of each complex held the residues of the binding pocket of HCA rigid and with an energy-minimized structure of the ligand. The binding energy decomposition contained the following terms: Coulombic interactions, van der Waals (vdW) interactions, bonded conformations (bond, angle, and torsion), H-bonding, lipophilic, $\pi-\pi$ stacking, and generalized Born solvation. Each component was computed separately for the ligand, the empty binding pocket of HCA, and the ligand-HCA complex and then appropriately summed to calculate each contribution to the total binding energy. The anionic charge on the ligand was computed using a fit to the electrostatic potential derived from quantum mechanics at the RHF/6-31G* level of theory, ${ }^{[19]}$ which has been shown to perform well with continuum solvation models. Energy terms are shown in Table S4.

\section{Biostructural analyses}

Protein Crystallization: Monoclinic crystals of HCA were prepared with the hanging drop diffusion method published by McKenna and coworkers, ${ }^{[3]}$ and the crystals of HCA were left undisturbed (at $\left.4{ }^{\circ} \mathrm{C}\right)$ until needed for soaking experiments.

Ligand Soaking Experiments: We soaked the crystals of HCA in saturated solutions of the benzo- and fluorobenzo-extended ligands using the procedure described previously. ${ }^{[2]}$ 
Table S4. Decomposition of the Free Energy of Binding for $\mathbf{H}_{4}$ BTA and F $_{4}$ BTA (in kcal mol ${ }^{-1}$ ).

\begin{tabular}{|c|c|c|c|c|c|c|c|c|}
\hline & Coulomb & vdW & Bonded & H-bond & Lipo & Stacking & Solvation & Total \\
\hline $\mathrm{H}_{4}$ BTA & -115.2 & -26.3 & 1.2 & -0.4 & -15.9 & 0.0 & 113.5 & -43.1 \\
\hline $\mathbf{F}_{4} \mathbf{B T A}$ & -109.4 & -27.5 & 1.3 & -0.3 & -15.4 & 0.0 & 105.3 & -46.1 \\
\hline Difference & 5.8 & -1.2 & 0.1 & 0.1 & 0.5 & 0.0 & -8.2 & -3.0 \\
\hline
\end{tabular}


X-ray Crystallography: X-ray diffraction data of each crystal was collected at Brookhaven National Laboratory on the ADSC Quantum Q315 CCD detector at the National Synchrotron Light Source (beamline X-25) in collaboration with the Mail-Program, Brookhaven National Laboratory. ${ }^{[20]}$ Reflections were indexed and integrated using HKL2000, and scaled using SCALEPACK. ${ }^{[21]}$

Solution of Crystal Structures: Diffraction data were analyzed using the CCP4i suite of crystallography software ${ }^{[22]}$ using previously published procedures. Table $\mathrm{S} 3$ summarizes the crystallographic details for each protein-ligand structure. Figure S3 shows the images of the binding pocket of HCA II occupied by the various arylsulfonamide ligands used in this study. Only protein residues within a $5 \AA$ distance from the ligands are shown. Figure S4 shows instructive overlays of crystal structures. 
(A)

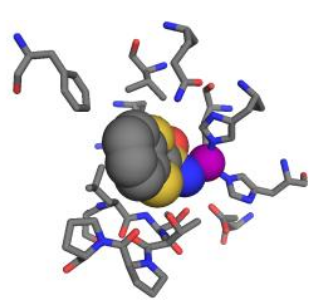

(D)

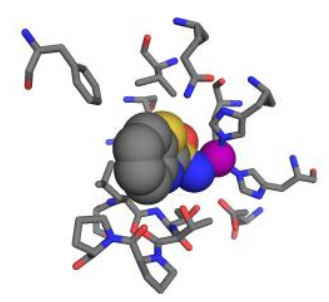

(B)

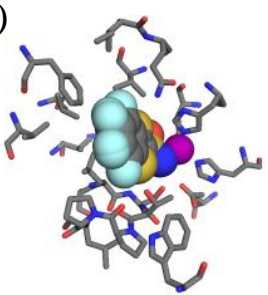

(E)

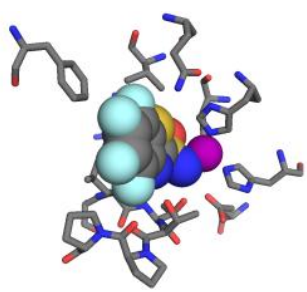

(C)

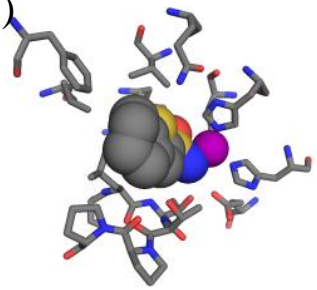

(F)

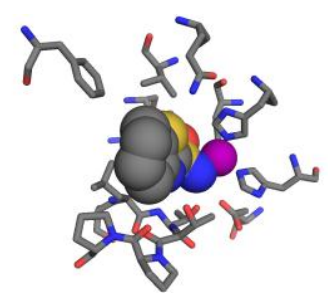

(G)

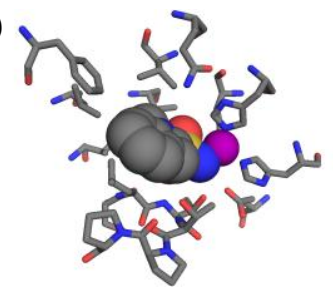

(H)

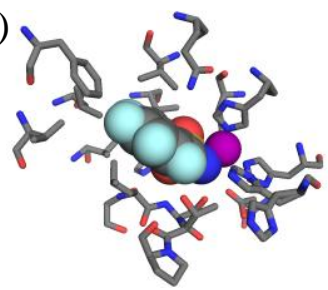

Figure S3. Occupied active site of HCA II found in crystal structure analyses of HCA

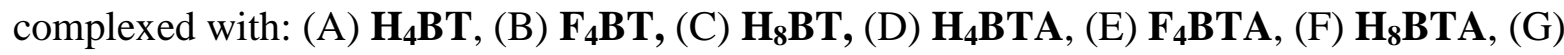
$\mathbf{H}_{\mathbf{4}} \mathbf{M B P}$, and (H) $\mathbf{F}_{\mathbf{4}} \mathbf{M B P}$. 
(A)

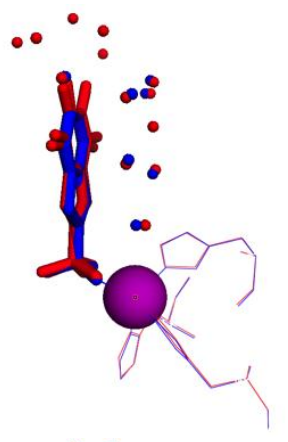

(C)

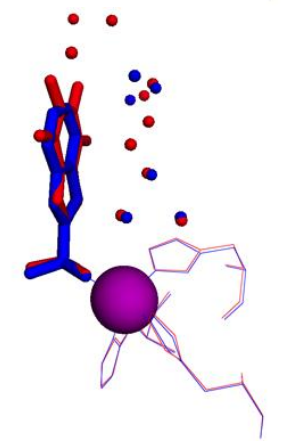

(E)

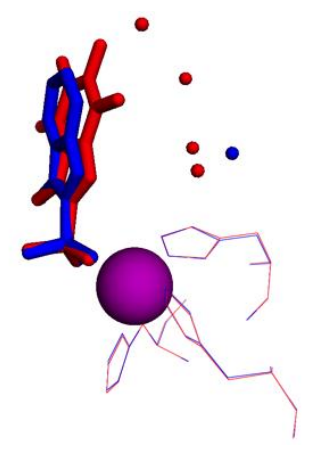

(B)

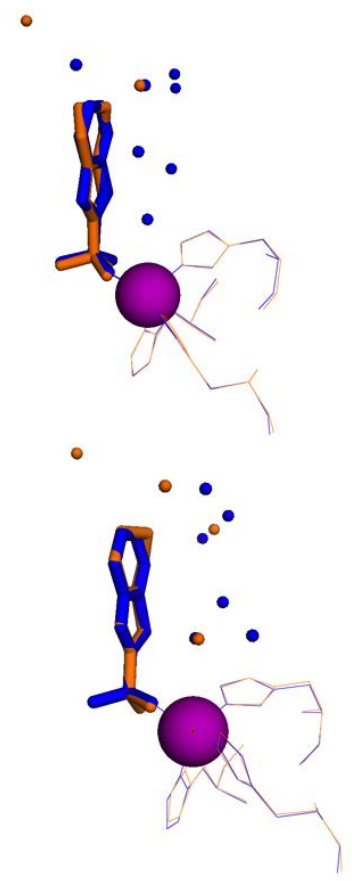

Figure S4. Overlays of benzo-, fluorobenzo-, and tetrahydrobenzo-extended ligands in the active site of HCA. Each overlay contains the crystallographically resolvable waters for: (A) $\mathbf{H}_{4} \mathbf{B T}$ and

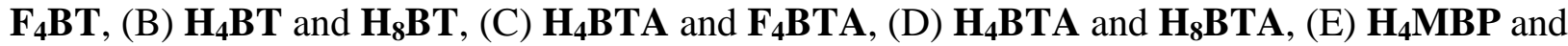
F 4 MBP. The benzo-extended ligands are shown in blue, the fluorobenzo-extended ligands in red, and tetrahydrobenzo-extended ligands in orange. In each image, the zinc atom is represented by a purple sphere. We included the three histidine residues that coordinate the zinc atom to show the heavy-atom alignment of proteins in each overlay. 


\section{References.}

[1] V. M. Krishnamurthy, G. K. Kaufman, A. R. Urbach, I. Gitlin, K. L. Gudiksen, D. B. Weibel, G. M. Whitesides, Chem. Rev. 2008, 108, 946.

[2] P. W. Snyder, J. Mecinovic, D. T. Moustakas, S. W. Thomas, M. Harder, E. T. Mack, M. R. Lockett, A. Heroux, W. Sherman, G. M. Whitesides, Proc. Nat. Acad. Sci., U.S.A. 2011, 108, 17889.

[3] A. H. Robbins, J. F. Domsic, M. Agbandje-McKenna, R. McKenna, Acta Crystallogr., Sect. D: Biol. Crystallogr. 2010, 66, 628.

[4] The pACA plasmid containing the HCA II gene was a kind gift of the Carol Fierke laboratory (University of Michigan, Department of Chemistry).

[5] S. K. Nair, T. L. Calderone, D. W. Christianson, C. A. Fierke, J. Biol. Chem. 1991, 266, 17320.

[6] J. Chern, Y. Leu, S. Wang, R. Jou, C. Lee, P. Tsou, S. Hsu, Y. Liaw, H. Lin, J. Med. Chem. 1997, 40, 2276.

[7] S. L. Graham, J. M. Hoffman, P. Gautheron, S. R. Michelson, R. L. Smith, J. M. Sondey, M. F. Sugrue, J. Med. Chem. 1990, 33, 749.

[8] M. Mader, L. Martin-Cabrejas, M. Richett, (Ed.: WIPO), ELI Lilly and Company, 2004.

[9] F. Mohamadi, M. Spees, G. Grindey, J. Med. Chem. 1992, 35, 3012.

[10] K. Chow, M. Garst, J. Holmes, (Ed.: USPTO), Allergan, 1994.

[11] I. M. Shirley, J. Fluorine Chem. 1994, 66, 51.

[12] J. G. Pomonis, C. L. Fatland, F. R. Taylor, J. Chem. Eng. Data 1976, 21, 233.

[13] L. Zhu, M. B. Zhang, J. Org. Chem. 2004, 69, 7371.

[14] C. Proenca, M. L. Serralheiro, M. E. Araujo, T. Pamplona, S. Santos, M. S. Santos, F. Frazao, J. Heterocycl. Chem. 2011, 48, 1287.

[15] V. M. Krishnamurthy, B. R. Bohall, C. Y. Kim, D. T. Moustakas, D. W. Christianson, G. M. Whitesides, Chem. Asian J. 2007, 2, 94.

[16] I. Massova, P. A. Kollman, Perspect. Drug Discovery Des. 2000, 18, 113.

[17] M. P. Jacobson, D. L. Pincus, C. S. Rapp, T. J. F. Day, B. Honig, D. E. Shaw, R. A. Friesner, Proteins: Struct., Funct., Bioinf. 2004, 55, 351.

[18] M. P. Jacobson, R. A. Friesner, Z. Xiang, B. Honig, J. Mol. Biol. 2002, 320, 597.

[19] D. F. Green, B. Tidor, J. Phys. Chem., B. 2003, 107, 10261.

[20] H. Robinson, A. S. Soares, M. Becker, R. Sweet, A. Heroux, Acta Crystallogr., Sect. D: Biol. Crystallogr. 2006, 62, 1336.

[21] Z. Otwinowski, W. Minor, Vol. Volume 276 (Ed.: W. C. Charles, Jr.), Academic Press, 1997, pp. 307.

[22] S. Bailey, Acta Crystallogr., Sect. D: Biol. Crystallogr. 1994, 50, 760. 